\title{
AVALIAÇÃO SANITÁRIA DE SEMENTES DE FEIJÃO USADAS POR AGRICULTORES FAMILIARES DA ZONA DA MATA
}

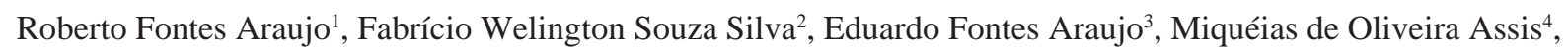
Valéria Rodrigues Veiga ${ }^{2}$

\begin{abstract}
RESUMO - O valor da semente relacionado à germinação e ao vigor é valorizado pelos agricultores. No entanto, o conhecimento do papel da semente como veículo de disseminação de patógenos é ainda limitado. Objetivou-se avaliar as qualidades sanitária e fisiológica de sementes de feijão usadas por agricultores familiares, comparando-as com as qualidades das sementes de cultivares da EPAMIG. Inicialmente, foram obtidas amostras de sementes de feijão de 74 agricultores familiares e da EPAMIG. As sementes foram avaliadas quanto às qualidades sanitária e fisiológica. Apenas $19 \%$ dos agricultores produziram sementes com vigor semelhante ao daquelas da EPAMIG. Dos 74 lotes de sementes, $83 \%$ apresentaram contaminação por fungos. Aqueles que não apresentaram ocorrência de fungos (17\%), coincidentemente, estão contidos naqueles $19 \%$ de lotes com alto vigor. Houve ocorrência do patógeno Colletotrichum lindemuthianum em $18 \%$ dos lotes, com incidência do fungo variando de 1 a $10 \%$ das sementes. A presença de Fusarium spp. foi verificada em $65 \%$ dos lotes de sementes; contaminação preocupante, com incidência do fungo nos lotes contaminados na faixa de 1 a $17 \%$. A incidência de Rhizoctonia solani foi menos preocupante do que a de Fusarium spp.; verificou-se a contaminação em $14 \%$ dos lotes, com a incidência do fungo nas sementes variando de 1 a 3\%. O fungo Macrophomina phaseolina ocorreu em $30 \%$ dos lotes; a incidência nas sementes ficou na faixa de 1 a $6 \%$. Em apenas $4 \%$ dos lotes foi encontrado o fungo Sclerotinea sclerotiorum; nesses lotes, a incidência nas sementes variou de 0,5 a $1 \%$. Dos fungos de armazenamento, constatou-se a ocorrência de Aspergillus spp. em $41 \%$ dos lotes, com a incidência do fungo variando de 1 a $18 \%$ nas sementes desses lotes. Já o Penicillium spp. foi diagnosticado em $39 \%$ dos lotes, com porcentagens de incidência nas sementes na faixa de 1 a 25 .
\end{abstract}

Palavras chave: fungos de armazenamento, fungos de campo, qualidade fisiológica.

\section{SANITARY EVALUATION OF BEANS SEEDS USED BY FAMILY FARMERS IN ZONA DA MATA}

\begin{abstract}
The value of seed related to germination and vigor is valued by farmers. However, knowledge of the role of seed as a vehicle for the spread of pathogens is still limited. The objective was to evaluate the health and physiological qualities of bean seeds used by family farmers, comparing them with the qualities of the EPAMIG cultivar seeds. Initially, samples of bean seeds were obtained from 74 family farmers and from EPAMIG. The seeds were evaluated for health and physiological qualities. Only 19\% of farmers produced seeds with similar vigor to those of EPAMIG. Of the 74 seed lots, $83 \%$ showed fungal contamination. Those that did not present fungi (17\%), coincidentally, are contained in those $19 \%$ of lots with high vigor. There was an occurrence of the pathogen Colletotrichum lindemuthianum in 18\% of the plots, with incidence of the fungus varying from 1 to $10 \%$ of the seeds. The presence of Fusarium spp was verified in $65 \%$ of the seed lots; contamination with contaminated lots in the range of 1 to $17 \%$. The incidence of Rhizoctonia solani was less worrisome than that of Fusarium spp; the contamination in 14\% of the lots was verified, with the incidence of the fungus in the seeds varying from 1 to $3 \%$. The fungus Macrophomina phaseolina occurred in $30 \%$ of the lots; the incidence in the seeds was in the range of 1 to $6 \%$. In only $4 \%$ of the plots was found the fungus Sclerotinea sclerotiorum; in those lots, the incidence in the
\end{abstract}

\footnotetext{
${ }^{1}$ Pesquisador, Empresa de Pesquisa Agropecuária de Minas Gerais, roberto.araujo@epamig.br

${ }^{2}$ Engenheiros-Agrônomos, Universidade Federal de Viçosa, fabricio.welington@ufv.br; valeria.veiga@ufv.br

${ }^{3}$ Professor Titular, Universidade Federal de Viçosa, efaraujo@ufv.br

${ }^{4}$ Doutorando em Fitotecnia, Universidade Federal de Viçosa, assis.agro@outlook.com
} 
seeds ranged from 0.5 to $1 \%$. From the storage fungi, the occurrence of Aspergillus spp was found in $41 \%$ of the lots, with fungus incidence varying from 1 to $18 \%$ in the seeds of these lots. Penicillium spp was diagnosed in 39\% of the plots, with incidence rates in the range of 1 to 25 .

Keywords: field fungi, physiological quality, storage fungi.

\section{INTRODUÇÃO}

Sementes de qualidade são a base de um agronegócio competitivo e de uma agricultura de sucesso. Sem elas, o Brasil não alcançaria, seguidamente, recordes de produção. Os crescentes níveis de utilização de tecnologia nas nossas lavouras têm como base a utilização de sementes legais, desenvolvidas e produzidas conforme os exigentes padrões controlados pelo MAPA (Brasil, 2013).

$\mathrm{O}$ valor da semente relacionado à germinação, ao vigor, ao potencial genético e à pureza física e varietal é valorizado pelos agricultores por agricultores e técnicos. No entanto, o conhecimento do papel da semente como veículo de disseminação de patógenos é ainda limitado, principalmente, entre os agricultores familiares. Os patógenos transportados pelas sementes, além de influenciarem negativamente a emergência e o vigor das plântulas, servem de inóculo inicial; sob condições ambientais favoráveis, podem originar epidemias graves e ocasionar reduções drásticas no rendimento da lavoura (Araujo \& Araujo, 2016).

Entre os patógenos das doenças de maior importância econômica para o feijoeiro, apenas os da ferrugem e do mosaico-dourado não são transmitidos pela semente. Segundo Lobo Júnior (2013), dentre as principais doenças transmitidas pelas sementes de feijão estão a antracnose (Colletotrichum lindemuthianum), a mancha angular (Pseudocercospora griseola), a murcha de curtobacterium (Curtobacterium flaccumfasciens pv. flaccumfasciens), a mancha de alternaria (Alternaria spp.), o crestamento bacteriano (Xanthomonas axonopodis pv. phaseoli), o mofo branco (Sclerotinia sclerotiorum), a murcha de fusário (Fusarium oxysporum f. sp. phaseoli), as podridões radiculares (Fusarium solani e Rhizoctonia solani), a mela (Thanatephorus cucumeris) e a podridão cinzenta da haste (Macrophomina phaseolina).

Considerando a sanidade das sementes, deve-se ter cuidado especial com as doenças antracnose, mofo-branco e crestamento-bacteriano-comum, pois estão presentes nos padrões de sementes de feijão estabelecidos pelo MAPA (Brasil, 2013). Caso ocorra na lavoura a presença desses patógenos acima dos padrões exigidos pela legislação, e se não forem tomadas medidas corretivas em tempo hábil, o campo de sementes certamente será condenado pelo responsável técnico.

Os patógenos associados às sementes são transportados de duas formas: internamente, infectando as sementes, e na sua superfície, infestando-as. Normalmente, a contaminação das sementes de feijão ocorre durante a trilha das plantas. Por exemplo, os escleródios de Sclerotinia sclerotiorum desprendem-se das plantas doentes durante a operação. O solo que se desprende das raízes durante a trilha e o aderido às sementes pode estar contaminado com Fusarium solani f. sp. phaseoli e Macrophomina phaseolina (Agarwal e Sinclair, 1987). Pedaços de plantas infectados podem transportar propágulos de Fusarium oxysporum f. sp. phaseoli. O inóculo transportado junto com às sementes (propágulos, pedaços de plantas infectadas e solos infestados) pode ser eliminado durante o beneficiamento do lote. Escleródios de S. sclerotiorum, que muitas vezes, têm o tamanho da semente de feijão, são mais difíceis de serem eliminados nesse processo (Paula Júnior \& Vieira, 2006).

Também são importantes os denominados fungos de armazenamento. Esses fungos desenvolvemse rapidamente, afetando, negativamente, a qualidade das sementes armazenadas. Dentro desse grupo de fungos, os gêneros Aspergillus e Penicillium são os mais comumente encontrados em sementes de feijão e chegam a ser responsáveis por perdas acima de $30 \%$ em grãos armazenados na América Latina, Ásia e África (Neergaard, 1997).

O uso de sementes com elevado padrão de sanidade é uma das principais medidas do controle desses patógenos. Conhecer os patógenos ocorrentes em sementes de feijão é importante quando se pensa na adoção de medidas para controle das doenças.

Objetivou-se avaliar as qualidades sanitária e fisiológica de sementes de feijão usadas pelos agricultores familiares da Zona da Mata, comparando-as com a sanidade, germinação e vigor das sementes de cultivares recomendadas e produzidas pela EPAMIG.

\section{MATERIAL E MÉTODOS}

O trabalho foi iniciado com a participação de técnicos da EMATER-MG, que obtiveram amostras 
de $500 \mathrm{~g}$ de sementes de diferentes lotes de feijão de 74 agricultores familiares dos seguintes municípios da Zona da Mata Mineira: Guiricema, Catas Altas da Noruega, Brás Pires, Lamim, Piranga, Presidente Bernardes, Oratórios, Urucânia, Ponte Nova, Viçosa, Paula Cândido, Teixeiras, Pedra do Anta, Leopoldina e Cataguazes.

No Laboratório de Sementes do Departamento de Fitotecnia da Universidade Federal de Viçosa, os lotes de sementes dos agricultores foram beneficiados em jogo de peneiras e, em seguida, determinou-se o teor de água das mesmas, pelo método da estufa a $105 \pm 3{ }^{\circ} \mathrm{C}$, por 24 horas, utilizando-se duas amostras de cada repetição, conforme as Regras para Análise de Sementes (Brasil, 2009).

Posteriormente, realizou-se, com as sementes dos agricultores e da EPAMIG, as seguintes avaliações:

- Teste de Germinação (TG): foi realizado segundo as Regras para Análise de Sementes (Brasil, 2009), utilizando-se o rolo de papel germitest, temperatura de $25^{\circ} \mathrm{C}$ e quatro repetições de 50 sementes. A avaliação foi feita no quarto e sétimo dia após a montagem e o resultado do total de plântulas normais expresso em porcentagem;

- Teste de Envelhecimento Acelerado (TEA): 200 sementes por repetição foram colocadas em cada caixa gerbox, contendo $40 \mathrm{~mL}$ de água destilada. O material foi acondicionado a $42^{\circ} \mathrm{C}$, durante 72 horas (Marcos Filho, 1999). Em seguida, quatro subamostras de 50 sementes por repetição foram submetidas ao TG;

- Teste de Sanidade: para detecção dos patógenos nas sementes empregou-se o método do "blotter test", de acordo com Dhingra e Sinclair (1995). Para cada cultivar se utilizaram 200 sementes sem desinfestação superficial; foram empregadas 25 sementes por caixa de acrílico tipo gerbox (11 x $11 \times 3,5 \mathrm{~cm})$, previamente desinfestadas com álcool a $70 \%$; cada caixa gerbox foi forrada com três folhas de papel de filtro, autoclavadas e pré-umedecidas com água destilada autoclavada, contendo 200 ppm de sulfato de estreptomicina; logo após, as caixas foram mantidas em temperatura ambiente $\left(25 \pm 3^{\circ} \mathrm{C}\right), \operatorname{com} 2000$ lux (12 horas de luz e 12 horas de escuro) pelo tempo de sete dias. As análises das sementes foram realizadas individualmente, ao microscópio estereoscópico e para certificação dos resultados fez-se o exame da morfologia dos fungos ao microscópio ótico para sua identificação, comparando-as com as informações disponíveis na literatura (Ellis, 1971; Booth, 1977; Sutton, 1980; Barnett \& Hunter, 1995). O número de colônias por sementes de cada fungo foi computado e transformado em percentagem de ocorrência.

O delineamento experimental utilizado foi $\mathrm{o}$ inteiramente casualizado, com quatro repetições. Os tratamentos foram as amostras de sementes de cada agricultor familiar e como testemunha sementes produzidas pela EPAMIG. Os resultados de germinação e vigor foram submetidos à análise de variância e as médias comparadas pelo teste de Dunnett a 5\% de probabilidade.

\section{RESULTADOS E DISCUSSÃO}

Os resultados de germinação, vigor e incidência de fungos em sementes produzidas pelos agricultores familiares e pela EPAMIG se encontram nas Tabelas de 1 a 4 . Verificou-se que $79 \%$ dos agricultores produziram sementes com germinação superior ou igual a $80 \%$, mínimo exigido por lei para comercialização. Também, 70\% dos agricultores produziram sementes com germinação superior a $85 \%$, valores que não diferiram estatisticamente daqueles das sementes produzidas pela EPAMIG, que foram superiores ou iguais a 95\%. Entretanto, apenas 19\% dos agricultores apresentaram sementes com alto vigor, pelo teste de envelhecimento acelerado, não diferindo estatisticamente (superior a 79\%) daqueles encontrados nas sementes produzidas pela EPAMIG (superior ou igual a 87\%). As razões para esse baixo vigor das sementes certamente estão relacionadas à maneira como os agricultores familiares conduzem as suas lavouras de produção, e estão amplamente discutidas em artigo cientifico especifico, em tramitação em periódico cientifico relacionado com a área em questão. Estes agricultores não produzem sementes, e sim, grãos. Apenas retiram uma amostra de grãos para serem plantados no ano agrícola seguinte.

usa do baixo rendimento do feijoeiro comum são as doenças, sendo quase todas elas disseminadas pelas sementes. Dos 74 lotes de sementes dos agricultores, $83 \%$ destes apresentaram algum tipo de contaminação por fungo. Ou seja, assim como nas sementes produzidas pela EPAMIG, apenas em $17 \%$ dos lotes de sementes dos agricultores não houve a ocorrência de fungos patogênicos; ressalta-se que o valor é muito próximo aos $19 \%$ de agricultores que produziram sementes com alto vigor, semelhante ao encontrado nas sementes produzidas pela EPAMIG (Tabelas de 1 a 4); também, coincidentemente, os $17 \%$ dos lotes que não apresentaram contaminação por fungos estão contidos naqueles $19 \%$ de lotes de sementes com alto vigor.

Além da baixa qualidade fisiológica das sementes, outra caDentre as principais doenças transmitidas por sementes de feijão: antracnose, mancha angular, a murcha de curtobacterium, mancha de alternaria, crestamento 
bacteriano, mofo branco, murcha de fusário, podridões radiculares de Fusarium solani e Rhizoctonia solani, mela e podridão cinzenta da haste (Lobo Júnior, 2013), cinco foram encontradas nas sementes dos agricultores que participaram deste estudo: antracnose (Colletotrichum lindemuthianum), Fusarium spp., podridão radicular (Rhizoctonia solani), mofo branco (Sclerotinia sclerotiorum) e podridão cinzenta da haste (Macrophomina phaseolina).

Tabela 1 - Germinação, vigor e incidência de fungos em sementes de feijão vermelho produzidas por agricultores e pela EPAMIG

\begin{tabular}{|c|c|c|c|c|c|c|c|c|c|c|}
\hline \multirow{2}{*}{$\begin{array}{l}\text { Lotes de } \\
\text { Sementes }\end{array}$} & \multicolumn{2}{|c|}{ Qualidade Fisiológica } & \multicolumn{8}{|c|}{ Incidência de Fungos (\%) } \\
\hline & $\begin{array}{c}\text { Germinação } \\
(\%)\end{array}$ & $\begin{array}{c}\text { Envelhecimento } \\
\text { Acelerado (\%) }\end{array}$ & $\begin{array}{l}\text { Aspergillus } \\
\text { spp. }\end{array}$ & $\begin{array}{l}\text { Penicillium } \\
\text { spp. }\end{array}$ & $\begin{array}{l}\text { Colletotrichum } \\
\text { lindemuthianum }\end{array}$ & $\begin{array}{l}\text { Fusarium } \\
\text { spp. }\end{array}$ & $\begin{array}{l}\text { Rhizoctonia } \\
\text { solani }\end{array}$ & $\begin{array}{l}\text { Macrophomina } \\
\text { phaseolina }\end{array}$ & $\begin{array}{l}\text { Sclerotinea } \\
\text { sclerotiorum }\end{array}$ & $\begin{array}{l}\text { Rizhopus } \\
\text { sp. }\end{array}$ \\
\hline Vermelho 1 & $92^{\mathrm{ns}}$ & $74^{*}$ & 2 & -- & -- & -- & 1 & -- & -- & - \\
\hline Vermelho 2 & $96^{\mathrm{ns}}$ & $58^{*}$ & -- & -- & -- & 1 & 2 & 1 & -- & -- \\
\hline Vermelho 3 & $90^{\text {ns }}$ & $82^{\mathrm{ns}}$ & -- & -- & -- & -- & -- & -- & -- & - \\
\hline Vermelho 4 & $96^{\text {ns }}$ & $62^{*}$ & -- & -- & -- & 2 & -- & -- & -- & -- \\
\hline Vermelho 5 & $89^{\text {ns }}$ & $68^{*}$ & -- & 2 & -- & -- & 1 & -- & -- & -- \\
\hline Vermelho 6 & $88^{\mathrm{ns}}$ & $43 *$ & -- & -- & -- & 5 & -- & -- & -- & -- \\
\hline Vermelho 7 & $96^{\text {ns }}$ & $73^{*}$ & -- & 1 & -- & 1 & -- & 1 & -- & -- \\
\hline Vermelho 8 & $98^{\mathrm{ns}}$ & $86^{\mathrm{ns}}$ & -- & -- & -- & -- & -- & -- & -- & -- \\
\hline Vermelho 9 & $90^{\text {ns }}$ & $69^{*}$ & 1 & 1 & -- & -- & -- & 1 & -- & -- \\
\hline Vermelho 10 & $91^{\text {ns }}$ & $58^{*}$ & -- & -- & -- & 5 & -- & -- & -- & -- \\
\hline Vermelho 11 & $96^{\mathrm{ns}}$ & $62^{*}$ & -- & -- & -- & 2 & -- & 1 & -- & -- \\
\hline Vermelho 12 & $98^{\mathrm{ns}}$ & $52 *$ & -- & -- & -- & 1 & 1 & -- & -- & -- \\
\hline Vermelho 13 & $98^{\mathrm{ns}}$ & $72 *$ & -- & -- & -- & 2 & -- & -- & -- & -- \\
\hline Vermelho 14 & $92^{\mathrm{ns}}$ & $53^{*}$ & -- & -- & -- & 3 & -- & -- & -- & -- \\
\hline Vermelho 15 & $00^{*}$ & $00^{*}$ & 7 & 5 & 1 & 16 & -- & 3 & -- & -- \\
\hline Vermelho 16 & $98^{\mathrm{ns}}$ & $81^{\text {ns }}$ & -- & -- & -- & -- & -- & -- & -- & -- \\
\hline Vermelho 17 & $96^{\text {ns }}$ & $86^{\mathrm{ns}}$ & -- & -- & -- & -- & -- & -- & -- & -- \\
\hline Vermelho 18 & $61^{*}$ & $32 *$ & 2 & -- & -- & 5 & 2 & 1 & 0,5 & 1 \\
\hline Vermelho 19 & $88^{\mathrm{ns}}$ & $55^{*}$ & 1 & 1 & -- & -- & -- & 1 & -- & 1 \\
\hline Vermelho 20 & $97^{\text {ns }}$ & $82^{\text {ns }}$ & -- & -- & -- & -- & -- & -- & -- & -- \\
\hline Vermelho 21 & $88^{\mathrm{ns}}$ & $38^{*}$ & -- & -- & -- & 2 & -- & 2 & -- & -- \\
\hline Vermelho 22 & $88^{\mathrm{ns}}$ & $68^{*}$ & 2 & -- & -- & -- & 1 & 1 & -- & -- \\
\hline Vermelho 23 & $98^{\text {ns }}$ & $74^{*}$ & 1 & -- & -- & 1 & -- & -- & -- & -- \\
\hline Vermelho 24 & $92^{\mathrm{ns}}$ & $72 *$ & -- & -- & -- & 3 & -- & -- & -- & -- \\
\hline Vermelho 25 & $89^{\text {ns }}$ & $34^{*}$ & -- & -- & -- & 2 & -- & 1 & -- & -- \\
\hline Vermelho 26 & $98^{\text {ns }}$ & $85^{\text {ns }}$ & -- & -- & -- & -- & -- & -- & -- & -- \\
\hline Vermelho 27 & $73^{*}$ & $28^{*}$ & -- & -- & -- & 9 & -- & 2 & -- & -- \\
\hline Vermelho 28 & $94^{\text {ns }}$ & $72 *$ & -- & -- & -- & -- & -- & 1 & -- & -- \\
\hline EPAMIG & 97 & 89 & -- & -- & -- & -- & -- & -- & -- & -- \\
\hline
\end{tabular}

Constatou-se a presença de Colletotrichum lindemuthianum em 13 lotes de sementes dos 74 agricultores; portanto, em $18 \%$ dos lotes. Nestes 13 lotes, a incidência do fungo variou de 1 a $10 \%$ das sementes (Tabelas de 1 a 4). 
O fungo Colletotrichum lindemuthianum (Sacc. Magnus) Cavara é causador da antracnose do feijoeiro, doença que, sob condições ideais, pode causar danos de até $90 \%$ na lavoura (Balardin, 1997), principalmente pelo plantio de sementes infectadas pelo fungo. Nas sementes de feijoeiro os sintomas se manifestam por manchas empardecidas e deprimidas, mais facilmente notadas nas sementes de tegumento claro. A associação entre a severidade da doença e a recuperação do fungo nas sementes pode estar ligada à época em que o patógeno ataca a cultura.

Tabela 2 - Germinação, vigor e incidência de fungos em sementes de feijão carioca produzidas por agricultores e pela EPAMIG

\begin{tabular}{|c|c|c|c|c|c|c|c|c|c|c|}
\hline \multirow{2}{*}{$\begin{array}{l}\text { Lotes de } \\
\text { Sementes }\end{array}$} & \multicolumn{2}{|c|}{ Qualidade Fisiológica } & \multicolumn{8}{|c|}{ Incidência de Fungos (\%) } \\
\hline & $\begin{array}{c}\text { Germinação } \\
(\%)\end{array}$ & $\begin{array}{c}\text { Envelhecimento } \\
\text { Acelerado (\%) }\end{array}$ & $\begin{array}{l}\text { Aspergillus } \\
\text { spp. }\end{array}$ & $\begin{array}{l}\text { Penicillium } \\
\text { spp. }\end{array}$ & $\begin{array}{l}\text { Colletotrichum } \\
\text { lindemuthianum }\end{array}$ & $\begin{array}{l}\text { Fusarium } \\
\text { spp. }\end{array}$ & $\begin{array}{l}\text { Rhizoctonia } \\
\text { solani }\end{array}$ & $\begin{array}{c}\text { Macrophomina } \\
\text { phaseolina }\end{array}$ & $\begin{array}{c}\text { Sclerotinea } \\
\text { sclerotiorum }\end{array}$ & $\begin{array}{l}\text { Rizhopus } \\
\text { sp. }\end{array}$ \\
\hline Carioca 1 & $33^{*}$ & $00^{*}$ & 14 & 19 & -- & 6 & -- & 1 & -- & -- \\
\hline Carioca 2 & $94^{\mathrm{ns}}$ & $66^{*}$ & -- & -- & -- & 1 & -- & -- & -- & -- \\
\hline Carioca 3 & $14^{*}$ & $02 *$ & 13 & 6 & 1 & 17 & -- & 4 & -- & -- \\
\hline Carioca 4 & $78^{*}$ & $16^{*}$ & -- & 5 & -- & 3 & 1 & -- & -- & 1 \\
\hline Carioca 5 & $96^{\mathrm{ns}}$ & $88^{\text {ns }}$ & -- & -- & -- & 1 & -- & -- & -- & -- \\
\hline Carioca 6 & $94^{\mathrm{ns}}$ & $68^{*}$ & -- & -- & 1 & 2 & -- & -- & -- & -- \\
\hline Carioca 7 & $94^{\mathrm{ns}}$ & $75^{*}$ & 1 & -- & -- & 2 & -- & -- & -- & -- \\
\hline Carioca 8 & $85^{*}$ & $67^{*}$ & 2 & 1 & -- & 2 & -- & -- & -- & -- \\
\hline Carioca 9 & $98^{\text {ns }}$ & $82^{\text {ns }}$ & -- & -- & -- & 1 & -- & -- & -- & -- \\
\hline Carioca 10 & $94^{\mathrm{ns}}$ & $72 *$ & -- & -- & -- & 2 & -- & -- & -- & -- \\
\hline Carioca 11 & $84^{*}$ & $65^{*}$ & -- & 2 & -- & -- & 2 & 1 & -- & -- \\
\hline Carioca 12 & $20^{*}$ & $06^{*}$ & 2 & -- & 1 & 4 & -- & 1 & -- & 1 \\
\hline Carioca 13 & $95^{\text {ns }}$ & $80^{\text {ns }}$ & -- & -- & -- & -- & -- & -- & -- & -- \\
\hline Carioca 14 & $88^{\mathrm{ns}}$ & $58^{*}$ & -- & 2 & -- & 1 & - & - & -- & -- \\
\hline Carioca 15 & $96^{\mathrm{ns}}$ & $83^{\text {ns }}$ & -- & -- & -- & -- & -- & -- & -- & -- \\
\hline Carioca 16 & $91^{\text {ns }}$ & $71^{*}$ & -- & -- & -- & 3 & -- & -- & -- & -- \\
\hline Carioca 17 & $74^{*}$ & $47^{*}$ & 1 & 2 & -- & 4 & -- & -- & -- & -- \\
\hline Carioca 18 & $87^{\text {ns }}$ & $61^{*}$ & 1 & -- & -- & 3 & -- & -- & 1 & -- \\
\hline Carioca 19 & $90^{\mathrm{ns}}$ & $78^{*}$ & 1 & -- & -- & -- & -- & -- & -- & -- \\
\hline Carioca 20 & $96^{\mathrm{ns}}$ & $85^{\text {ns }}$ & -- & -- & -- & -- & -- & -- & -- & -- \\
\hline EPAMIG & 95 & 87 & -- & -- & -- & -- & -- & -- & -- & -- \\
\hline
\end{tabular}

* Valor difere da testemunha pelo teste de Dunnet $(\mathrm{p}<0,05)$.

${ }^{\text {ns }}$ Valor não difere da testemunha pelo teste de Dunnet $(\mathrm{p}<0,05)$.

O fungo $C$. lindemuthianum é considerado uma praga não quarentenária regulamentável, com nível de tolerância zero para que um lote considerado semente e não grão, pois se trata de uma praga de alto risco (Brasil, 2013). Considerando uma semeadura de 400.000 sementes de feijão por hectare, um índice de ocorrência de $C$. lindemuthianum da ordem de $0,25 \%$, significa a introdução de 1.000 focos primários de infecção na referida área (Machado, 1994).
Rey et al. (2009) verificaram que o fungo C. lindemuthianum apresenta taxas de transmissão semente-planta que variam de 70 a $80 \%$, e o patógeno, independentemente de raças, pode interferir negativamente no sistema radicular do feijoeiro. De acordo com estudos relacionando níveis de inóculo de $C$. lindemuthianum em sementes de feijão, com a severidade da doença em campo, Talamini (2003) observou que as menores taxas de progresso da doença foram observadas nos níveis 
de inóculo de 0 a $0,5 \%$ e as maiores taxas de progresso da doença foram observadas nos níveis de 0,5 a 4,0\%, comprometendo a produção. Viana (2016) verificou, em diferentes amostras de sementes de feijão, níveis de inóculo de C. lindemuthianum variando de 9,5 a 37,5\%; \%, muito acima de níveis de tolerância estudados por outros autores.
Uma alternativa para a obtenção de sementes de feijão de alta qualidade sanitária e fisiológica pode ser viabilizada pela produção em várzeas tropicais com irrigação por subirrigação durante o inverno, juntamente com a utilização das práticas recomendadas para eliminação dos patógenos transmissíveis pela semente, descritas no esquema de produção preconizado pela Embrapa Arroz e Feijão (Rava et al., 2002).

Tabela 3 - Germinação, vigor e incidência de fungos em sementes de feijão preto produzidas por agricultores e pela EPAMIG

\begin{tabular}{|c|c|c|c|c|c|c|c|c|c|c|}
\hline \multirow{2}{*}{$\begin{array}{l}\text { Lotes de } \\
\text { Sementes }\end{array}$} & \multicolumn{2}{|c|}{ Qualidade Fisiológica } & \multicolumn{8}{|c|}{ Incidência de Fungos (\%) } \\
\hline & $\begin{array}{c}\text { Germinação } \\
(\%)\end{array}$ & $\begin{array}{c}\text { Envelhecimento } \\
\text { Acelerado (\%) }\end{array}$ & $\begin{array}{l}\text { Aspergillus } \\
\text { spp. }\end{array}$ & $\begin{array}{l}\text { Penicillium } \\
\text { spp. }\end{array}$ & $\begin{array}{l}\text { Colletotrichum } \\
\text { lindemuthianum }\end{array}$ & $\begin{array}{l}\text { Fusarium } \\
\text { spp. }\end{array}$ & $\begin{array}{l}\text { Rhizoctonia } \\
\text { solani }\end{array}$ & $\begin{array}{c}\text { Macrophomina } \\
\text { phaseolina }\end{array}$ & $\begin{array}{l}\text { Sclerotinea } \\
\text { sclerotiorum }\end{array}$ & $\begin{array}{l}\text { Rizhopus } \\
\text { sp. }\end{array}$ \\
\hline Preto 1 & $90^{\text {ns }}$ & $18^{*}$ & 3 & 2 & 1 & -- & -- & 1 & -- & -- \\
\hline Preto 2 & $85^{*}$ & $48^{*}$ & -- & 3 & -- & 1 & -- & -- & -- & 2 \\
\hline Preto 3 & $92^{\text {ns }}$ & $12 *$ & 2 & -- & 2 & 4 & -- & -- & -- & - \\
\hline Preto 4 & $81 *$ & $21^{*}$ & 3 & 2 & -- & 2 & -- & 2 & -- & 1 \\
\hline Preto 5 & $92^{\mathrm{ns}}$ & $66^{*}$ & -- & 2 & -- & 2 & -- & -- & -- & -- \\
\hline Preto 6 & $87^{\text {ns }}$ & $47^{*}$ & 1 & 4 & -- & -- & 2 & -- & -- & -- \\
\hline Preto 7 & $96^{\text {ns }}$ & $86^{\mathrm{ns}}$ & -- & -- & -- & -- & -- & -- & -- & -- \\
\hline Preto 8 & $95^{\text {ns }}$ & $82^{\mathrm{ns}}$ & -- & -- & -- & -- & -- & -- & -- & -- \\
\hline Preto 9 & $96^{\text {ns }}$ & $78^{*}$ & -- & 1 & -- & 1 & -- & -- & -- & -- \\
\hline Preto 10 & $00^{*}$ & $00^{*}$ & 2 & -- & 10 & 6 & -- & -- & -- & -- \\
\hline Preto 11 & $95^{\text {ns }}$ & $81^{\text {ns }}$ & -- & -- & -- & -- & -- & -- & -- & -- \\
\hline Preto 12 & $78^{*}$ & $42 *$ & 3 & 2 & 2 & 3 & -- & -- & -- & -- \\
\hline Preto 13 & $91^{\text {ns }}$ & $67 *$ & -- & 2 & -- & 2 & -- & -- & -- & -- \\
\hline Preto 14 & $92^{\text {ns }}$ & $74^{*}$ & -- & 1 & -- & 1 & -- & -- & -- & -- \\
\hline Preto 15 & $75^{*}$ & $58^{*}$ & 2 & 1 & -- & 2 & -- & -- & -- & -- \\
\hline EPAMIG & 96 & 89 & -- & -- & -- & -- & -- & -- & -- & -- \\
\hline
\end{tabular}

* Valor difere da testemunha pelo teste de Dunnet $(\mathrm{p}<0,05)$

${ }^{n s}$ Valor não difere da testemunha pelo teste de Dunnet $(p<0,05)$.

Sugere-se, também, para que seja evitado a introdução desse patógeno em novas áreas de cultivo de feijão, rigor e monitoramento constante da qualidade das sementes comercializadas, submetendo-as à análise de sanidade feita por laboratórios credenciados.

A presença de Fusarium spp. foi verificada em sementes de 48 lotes dos agricultores familiares; uma contaminação preocupante, com a presença do fungo em $65 \%$ dos lotes. A incidência do fungo, dentro dos lotes contaminados, variou de 1 a 17\% (Tabelas de 1 a 4).

De acordo com Silva et al. (2008), quando fungos do gênero Fusarium sp. são caracterizados como patogênicos, estes apresentam grande importância na cultura, sendo causador de doenças como murcha do fusarium e podridrão radicular, com capacidade de sobreviver no solo, na forma de clamidósporos, e ser disseminado por sementes contaminadas e/ou infectadas.

Apesar de significativa, a incidência de Rhizoctonia solani foi menos preocupante do que a de Fusarium spp. Verificou-se a presença do patógeno em 10 lotes de sementes (14\%); destes lotes contaminados, a incidência nas sementes variou de 1 a $3 \%$ apenas (Tabelas de 1 a 4$)$. 
Tabela 4 - Germinação, vigor e incidência de fungos em sementes de diferentes tipos de feijão produzidas por agricultores familiares e pela EPAMIG

\begin{tabular}{|c|c|c|c|c|c|c|c|c|c|c|}
\hline \multirow{2}{*}{$\begin{array}{l}\text { Lotes de } \\
\text { Sementes }\end{array}$} & \multicolumn{2}{|c|}{ Qualidade Fisiológica } & \multicolumn{8}{|c|}{ Incidência de Fungos (\%) } \\
\hline & $\begin{array}{c}\text { Germinação } \\
(\%)\end{array}$ & $\begin{array}{c}\text { Envelhecimento } \\
\text { Acelerado (\%) }\end{array}$ & $\begin{array}{l}\text { Aspergillus } \\
\text { spp. }\end{array}$ & $\begin{array}{l}\text { Penicillium } \\
\text { spp. }\end{array}$ & $\begin{array}{l}\text { Colletotrichum } \\
\text { lindemuthianum }\end{array}$ & $\begin{array}{l}\text { Fusarium } \\
\text { spp. }\end{array}$ & $\begin{array}{l}\text { Rhizoctonia } \\
\text { solani }\end{array}$ & $\begin{array}{l}\text { Macrophomina } \\
\text { phaseolina }\end{array}$ & $\begin{array}{c}\text { Sclerotinea } \\
\text { sclerotiorum }\end{array}$ & $\begin{array}{l}\text { Rizhopus } \\
\text { sp. }\end{array}$ \\
\hline Manteigado & $89^{\text {ns }}$ & $74 *$ & 1 & 2 & - & 2 & -- & -- & -- & -- \\
\hline Branco & $00^{*}$ & $00^{*}$ & 18 & 25 & 2 & 7 & -- & 2 & -- & -- \\
\hline Enxofrinho 1 & $88^{\mathrm{ns}}$ & $47^{*}$ & -- & -- & - & 6 & -- & 1 & -- & -- \\
\hline Enxofrinho 2 & $76^{*}$ & $23 *$ & 3 & 4 & -- & 1 & 3 & -- & -- & 2 \\
\hline Jalo & $94^{\text {ns }}$ & $72 *$ & 1 & 2 & 2 & -- & -- & -- & -- & -- \\
\hline Rapé & $98^{\mathrm{ns}}$ & $84^{\text {ns }}$ & -- & -- & -- & -- & -- & -- & -- & -- \\
\hline Rosinha & $94^{\text {ns }}$ & $75^{*}$ & 1 & 1 & - & -- & -- & - & - & - \\
\hline Roxinho 1 & $90^{\mathrm{ns}}$ & $72 *$ & - & -- & - & 2 & -- & - & - & - \\
\hline Roxinho 2 & $48^{*}$ & $16^{*}$ & 6 & -- & 9 & 16 & -- & 6 & -- & -- \\
\hline Roxinho 3 & $76^{*}$ & $28^{*}$ & 2 & 4 & 1 & -- & -- & -- & 0,5 & -- \\
\hline Verde & $02 *$ & $00^{*}$ & 8 & 11 & 2 & 8 & -- & 3 & -- & -- \\
\hline EPAMIG & 95 & 87 & -- & -- & -- & -- & -- & -- & -- & -- \\
\hline
\end{tabular}

* Valor difere da testemunha pelo teste de Dunnet $(\mathrm{p}<0,05)$.

${ }^{\mathrm{ns}}$ Valor não difere da testemunha pelo teste de Dunnet $(\mathrm{p}<0,05)$.

Em feijoeiro comum as principais consequências deste complexo formado por Rhizoctonia solani e Fusarium solani f. sp. Phaseoli se concentram na perda de raízes, redução do estande e vigor das plântulas (Menten, 1995).

Pedrosa \& Teliz (1992) citaram que, sozinhos, Rhizoctonia solani e Fusarium solani causaram 25 e $8 \%$ de morte emergente, respectivamente, mas quando inoculados juntos apresentaram efeito sinérgico causando $67 \%$ de morte das plantas de feijão.

Verificou-se, também, a presença de Macrophomina phaseolina, fungo responsável pela podridão cinzenta da haste. A ocorrência do fungo aconteceu em 22 lotes de sementes dos agricultores; portanto, em 30\% dos lotes. A incidência, nos lotes contaminados, ficou na faixa de 1 a $6 \%$ (Tabelas de 1 a 4 ).

O fungo Macrophomina phaseolina (Tasse) Goid, agente causal da podridão cinzenta do caule, é considerado, pelos danos causados, um dos principais patógenos de sementes de feijão (Menezes, 1987). É um fungo polífago, com grande variabilidade patogênica e alta capacidade de sobrevivência em condições adversas. A fonte de inóculo primária é constituída pela semente infectada, restos de cultura colonizada pelo micélio do fungo e escleródios (Dhingra \& Sinclair, 1978).
No nordeste brasileiro, onde as plantas estão sujeitas a altas temperaturas e descréscimo da umidade do solo, condições que favorecem o desenvolvimento do patógeno, esta doença é um dos fatores limitantes ao cultivo de feijão (Dhingra \& Sinclair, 1978).

Segundo Vechiato et al. (2000), a redução significativa da emergência constatada em casa de vegetação, em solo com inóculo, vem demonstrar a importância da presença do patógeno no solo utilizado para o plantio de feijão. Este fato evidencia que o tratamento de sementes com fungicidas visando reduzir ou eliminar o inóculo em sementes é muito importante, pois evita infestação do solo, além de proteger a emergência de sementes contra fungos de solo. Dhingra \& Sinclair (1978) preconizaram como medida de controle da podridão cinzenta do caule, o emprego de semente de boa qualidade sanitária, tratamento de sementes com fungicidas e adoção de práticas culturais, visando reduzir o potencial de inóculo do patógeno.

Em apenas três lotes de sementes dos agricultores familiares foi encontrado o fungo Sclerotinea sclerotiorum ( $4 \%$ dos lotes); nesses três lotes, a incidência variou de 0,5 a 1\% (Tabelas de 1 a 4). Apesar das baixas taxas de ocorrência de Sclerotinea sclerotiorum, as áreas dos agricultores de onde tiveram origem os três lotes de sementes devem ser evitadas por se tratar de um patógeno com grande poder 
destrutivo e capacidade de sobrevivência por muitos anos, por meio dos escleródios (Hall \& Steadman, 1994).

O mofo branco e a antracnose, por estarem presentes nas normas e nos padrões de sementes de feijão (Brasil, 2013), são doenças que devem ser, constantemente, monitoradas, principalmente nos campos de produção de sementes. Na lavoura, caso ocorra a presença dos patógenos causadores dessas duas doenças em porcentagem acima dos padrões exigidos pelo MAPA (Brasil, 2013), e se não forem tomadas medidas corretivas, em tempo hábil, o campo de sementes certamente será condenado pelo responsável técnico.

Com o advento da irrigação, a cultura do feijão passou a ter plantio contínuo, em três épocas do ano, possibilitando que um complexo de doenças causadas por patógenos veiculados pelo solo adquirisse grande importância. Dentre estas doenças, tem-se as fusarioses e o mofo branco, causado por Sclerotinia sclerotiorum. Trata-se de uma constatação preocupante, pois este fungo tem a capacidade de sobreviver no solo, na forma de clamidósporos, e é disseminado através de sementes contaminadas e/ ou infectadas (Hall \& Steadman, 1994).

Comparando-se os resultados obtidos para a qualidade fisiológica e a incidência de fungos, Silva et al. (2008) verificaram que, em geral, os altos índices de vigor dos genótipos Bambu e BRS Radiante podem estar relacionados com a baixa incidência de fungos e, principalmente, com a ausência de Fusarium sp. e $S$. sclerotiorum.

Os patógenos de campo associados, externa ou internamente, às sementes, também podem causar morte de sementes após o plantio devido à rapidez de desenvolvimento e alta agressividade de determinados grupos de patógenos na semente e que retornam à atividade assim que encontram condições favoráveis (solo, clima), matando a semente antes que ela evidencie os primeiros indícios de ter iniciado a germinação pela ação de enzimas e toxinas (Menten, 1995).

A constatação da presença de microrganismos, mesmo patogênicos, na semente, não é suficiente para garantir que ele irá infectar a planta proveniente dessa semente, pois vários são os fatores que influenciam na transmissão, como a quantidade de inóculo, microrganismos do solo, bem como da própria semente, fatores físicos do solo, condições climáticas e o tempo de sobrevivência do patógeno na semente. Entretanto, a associação patógenosemente indica um potencial de transmissão e possível estabelecimento da doença no campo, como várias bactérias fitopatogênicas e de fungos dos gêneros Colletotrichum,
Phaeoisariopsis, Alternaria, Macrophomina, Fusarium, Rhizoctonia, Sclerotium, Sclerotinia e de vírus como o do mosaico comum, transmitidos pela semente (Rava et al., 2002; Torres \& Bringel, 2005).

Também foi encontrado nos lotes de sementes o Rizhopus sp. O fungo foi diagnosticado em sete lotes (9\%), com incidência variando de 1 a $2 \%$ (Tabelas de 1 a 4). O gênero Rhizopus sp., apesar de não possuir importância econômica nas sementes, pode, como contaminante, dificultar a detecção de patógenos, por cobrir as sementes com rápido crescimento (Torres \& Bringel, 2005).

Além dos fungos de campo, discutidos anteriormente, foram encontrados nos lotes de sementes dos agricultores familiares os chamados fungos de armazenamento, dos quais dois gêneros se destacam: Aspergillus e Penicillium.

Constatou-se a ocorrência de Aspergillus spp. em 30 lotes de sementes (41\%); a incidência do fungo variou de 1 a 18\% nas sementes desses lotes. Já o Penicillium spp. foi diagnosticado em 29 lotes (39\%), com porcentagens de contaminação variando de 1 a 25 nas sementes dos lotes (Tabelas de 1 a 4). Esporos e micélios desses fungos, normalmente, já estão presentes na superfície da semente antes do armazenamento.

Os chamados fungos de campo têm sua incidência reduzida durante o armazenamento; por outro lado, fungos de armazenamento desenvolvem-se, rapidamente, durante esta etapa afetando, negativamente, a qualidade das sementes armazenadas (Santos et al., 2018). Marino \& Mesquita (2009), estudando a microflora em sementes de feijão comum provenientes do Estado de Sergipe, verificaram a presença de Aspergillus sp. (0,5 a 2,0\%) em todas as variedades e Penicillium sp. (0,5 a 13,5\%), nas variedades IPA11 e Carioca Rajado. Em estudo com sementes de feijão provenientes do municípo de Tangará da Serra - MT. Almeida et al. (2013) verificaram que os fungos Fusarium sp. e Aspergillus sp. foram os que ocorreram com maior incidência, em todas as cultivares avaliadas.

Os fungos de armazenamento são os principais responsáveis pela perda da viabilidade das sementes armazenadas com teor de água superior a um valor crítico, particular para cada espécie fúngica. Estes fungos podem promover uma série de injúrias tais como enfraquecimento ou morte do embrião, reduzindo a germinação das sementes e a emergência das plântulas (Tanaka \& Corrêa, 1982), aquecimento da massa de grãos e apodrecimento (Dhingra,1985), descoloração de parte ou de todo o grão, transformações bioquímicas, modificações celulares, e em sua maioria atacam, principalmente, o embrião de sementes. 
Sementes com alto teor de água tendem a perder sua viabilidade mais rapidamente, pois ocorre uma intensificação da atividade respiratória, consumindo suas reservas nutritivas, ocorrendo, então, liberação de calor que torna o ambiente de armazenamento propício ao aparecimento de agentes patogênicos. A temperatura ótima para o crescimento e desenvolvimento dos fungos de armazenamento se encontra entre 28 e $35^{\circ} \mathrm{C}$, estando a máxima e a mínima entre 50 e $55^{\circ} \mathrm{C}$ e 0 e $5^{\circ} \mathrm{C}$, respectivamente (Dhingra, 1985). A atividade de fungos é, prontamente, reduzida com a redução da temperatura e algumas espécies ampliam sua população 10 a 20 vezes mais rápido, quando de $15,6^{\circ} \mathrm{C}$ passam a 32,2 ${ }^{\circ} \mathrm{C}$. Segundo Bewley \& Black (1994), cada espécie de fungo necessita de um limite mínimo de umidade relativa, abaixo do qual não se desenvolve; estes fungos não se desenvolvem em sementes com teor de água que esteja em equilíbrio com umidade relativa do ambiente abaixo de 68\%; assim, eles não são responsáveis por deterioração que ocorra em sementes amiláceas, como o feijão, com teor de água abaixo de $13 \%$.

O tratamento das sementes antes da semeadura é uma medida preventiva importante para o controle desses patógenos e ainda daqueles que sobrevivem no solo. Os patógenos localizados na superfície das sementes são facilmente controlados mediante o tratamento com fungicidas protetores. Para o controle de patógenos localizados internamente nas sementes, é recomendado o uso de fungicidas sistêmicos. A mistura de fungicida sistêmico com protetor é recomendável para ampliar o leque de patógenos controlados e diminuir o risco de eles desenvolverem resistência ao fungicida. O tratamento de sementes de feijão com fungicidas deve ser feito com produtos recomendados e registrados para a cultura.

Além dos tratamentos químicos das sementes e das plantas e de outras estratégias de controle, o planejamento e a implementação de procedimentos adequados nas fases de campo, principalmente a realização do roguing, para eliminação de plantas doentes e atípicas, e cuidados na colheita e pós-colheita podem garantir um produto final de alta qualidade sanitária.

\section{CONCLUSÕES}

Apenas $19 \%$ dos agricultores produziram sementes de feijão com vigor semelhante ao daquelas produzidas pela EPAMIG.

Dos 74 lotes de sementes dos agricultores familiares, $83 \%$ destes apresentaram algum tipo de contaminação por fungo.
Os lotes que não apresentaram ocorrência de fungos patogênicos (17\%), assim como as sementes da EPAMIG, coincidentemente, estão contidos naqueles 19\% de lotes de sementes com alto vigor.

Houve ocorrência do patógeno Colletotrichum lindemuthianum em $18 \%$ dos lotes de sementes dos agricultores, com incidência do fungo variando de 1 a $10 \%$ das sementes.

A presença de Fusarium spp. foi verificada em $65 \%$ dos lotes de sementes; contaminação preocupante, com incidência do fungo nos lotes contaminados na faixa de 1 a $17 \%$.

A incidência de Rhizoctonia solani foi menos preocupante do que a de Fusarium spp.; verificou-se a contaminação em $14 \%$ dos lotes, com a incidência do fungo nas sementes variando de 1 a $3 \%$.

O fungo Macrophomina phaseolina ocorreu em $30 \%$ dos lotes de sementes; a incidência nos lotes contaminados ficou na faixa de 1 a $6 \%$.

Em apenas 4\% dos lotes de sementes foi encontrado o fungo Sclerotinea sclerotiorum; nesses lotes, a incidência nas sementes variou de 0,5 a $1 \%$.

Dos fungos de armazenamento, constatou-se a ocorrência de Aspergillus spp. em 41\% dos lotes, com a incidência do fungo variando de 1 a $18 \%$ nas sementes desses lotes. Já o Penicillium spp. foi diagnosticado em 39\% dos lotes, com porcentagens de incidência nas sementes na faixa de 1 a 25 .

\section{AGRADECIMENTOS}

À FAPEMIG, pelo apoio financeiro.

\section{LITERATURA CITADA}

AGARWAL, V.K.; SINCLAIR, J.B. Principles of seed pathology. Boca Raton, CRC, 1987. 176p.

ALMEIDA, A.P. V.; SILVA, E.S.; SILVA, V.P. et al. Qualidade física, fisiológica e sanitária de sementes de feijoeiro (Phaseolus vulgaris L.) provenientes do municípo de Tangará da Serra - MT. Enciclopédia Biosfera, v.9, n.17, p. 2241-2249, 2013.

ARAUJO, R.F.; ARAUJO, E.F. Produção de Sementes. In: CARNEIRO, J.E.; PAULA JÚNIOR, T.J.; BORÉM, A. (Ed.). Feijão: do plantio à colheita. Viçosa: Ed. UFV, 2016. p.356-384. 
BALARDIN, R. S.; JAROSZ, A. M.; KELLY, J. D. Virulence and Molecular Diversity in Colletotrichum lindemuthianum from South Central, and North America. Phytopathology, v.87, n.12, p.1184-1191, 1997.

BARNETT, H.L.; HUNTER, B.B. Illustrated genera of fungi imperfect. Boca Ratón: CRC Press, 1995. 433p.

BEWLEY, J.D.; BLACK, M. Seeds: physiology of development and germination. $2^{\mathrm{a}}$ ed. New York: Plenum Press, 1994. 445p.

BOOTH, C. Fusarium: laboratory guide to the identification of the major species. Kew: Commonwealth Mycological Institute, 1977. 58p.

BRASIL. Anexo XI - Padrões para a produção e a comercialização de sementes de feijão. In: Instrução Normativa $\mathrm{n}^{\circ} 45$ do MAPA, de 17 de setembro de 2013. Ministério da Agricultura Pecuária e Abastecimento. Secretaria de Defesa Agropecuária. Brasília. 2013. p.14-15.

BRASIL. Ministério da Agricultura, Pecuária e Abastecimento. Regras para análise de sementes. Brasília: Mapa/ACS. 2009. 399p.

DHINGRA, O.D. Prejuízos causados por microorganismos durante o armazenamento de sementes. Revista Brasileira de Sementes, v.7, n.1, p.139-145, 1985.

DHINGRA, O.; SINCLAIR, J.B. Basic plant pathology methods. Boca Raton, CRC, 1995. 433p.

DHINGRA, O.D. \& SINCLAIR, J.B. Biology and pathology of Macrophomina phaseolina. Viçosa: UFV, 1978. 166p.

ELLIS, M.B. Dematiaceous hyphomycetes. Surrey: Commonwealth Mycological Institute, 1971. 608p.

HALL, R.; STEADMAN, J. R. White mold. In: HALL, R. (Ed.) Compendium of bean diseases. 2. Ed. Saint Paul: APS Press, 1994. p.28-29.

LOBO JÚNIOR, M. (Ed.). Árvore do conhecimento: Feijão - Sementes. Brasília, DF: Embrapa, 2013. https:// www.agencia.cnptia.embrapa.br/gestor/feijao/arvore/ CONTAG01_73_27820049337.html. (acessado em 15 de abril de 2019).

MACHADO, J.C. Padrões de tolerância de patógenos associados à semente. Revisão Anual de Patologia de Planta, n.2, p.229-263, 1994.

MARCOS FILHO, J. KRZYZANOWSKI, F.C.; VIEIRA, R.D.; FRANÇA-NETO, J.B. In: Teste de envelhecimento acelerado (Ed.). Vigor de sementes: conceitos e testes. Londrina: ABRATES. 1999. cap.3, p.1-24.

MARINO, R.H.; MESQUITA, J.B.; ANDRADE, K.V.S.; COSTA, N.A.; AMARAL, L.A. Incidência de fungos em sementes de Phaseolus vulgaris L. provenientes do Estado de Sergipe. Rev. Bras. Ciênc. Agrár. v.3, n.1, p.26-30, 2008.

MENEZES, J.R. Testes de sanidade de sementes de feijão. In: Soave, J. (Ed.) Patologia de sementes. Campinas, Fundação Cargill, 1987, p.395-405.

MENTEN, J.O.M. Patógenos em sementes: deteç̧ão, danos e controle químico. São Paulo: Ciba Agro, 1995. 321p.

NEEGARD, P. Seed pathology. London: Mac Millan Press, 1997. V. 2. 839 p.

PAULA JÚNIOR, T.J.; VIEIRA, R.F. 2006. Semente: importante veículo de disseminação de patógenos de feijão. In: VIEIRA, C.; PAULA JÚNIOR, T.J.; BORÉM, A. Feijão. 2ed. Viçosa: EDITORA UFV, p.437-476.

PEDROSA, A.; TELIZ, D. Patogenicidad relatia de Rhizoctonia solani, Fusarium solani, Pythium spp. y Macrophomina phaseolina em frijol (Phaseolus vulgaris L.) bajo condicioes de invernadero. Revista Mexicana de Fitopatologia, v.10, p.134-138, 1992.

RAVA, C.A.; COSTA, J.G.C.; AIDAR, H.; KLUTHCOUSKI, J. Produção de sementes de feijoeiro comum livres de Colletotrichum lindemuthianum em várzeas tropicais irrigadas por subirrigação. Embrapa Arroz e Feijão. 2002. 14 p. (Boletim de Pesquisa e Desenvolvimento).

REY, M.S.; LIMA, N.B.; SANTOS, J.; PIEROBOM, C.R. Transmissão semente-plântula de colletotrichum lindemuthinum em feijão (Phaseolus vulgaris). Arq. Inst. Biol., v.76, n.3, p.465-470. 2009.

SANTOS, K.M.; PEIXOTP, G.H.S.; PIRES, L.M. ET AL. Ocorrência de fungos em sementes de feijão comum 'pérola'. Tecnol. \& Ciên. Agropec., v.12, n.2, p.71-75. 2018.

SILVA, G.C.; GOMES, D.P.; KRONKA, A.Z.; MORAES, M.H. Qualidade fisiológica e sanitária de sementes de feijoeiro (Phaseolus vulgaris L.) provenientes do estado de Goiás. Semina: Ciências Agrárias, v. 29, n. 1, p. 29-34, 2008.

SUTTON, B.C. The Coelomycetes. Surrey: CABI Publications, 1980. 696p.

TALAMINI, V. Progresso espacial e temporal da antracnose a partir de diferentes níveis de inóculo inicial em sementes de feijoeiro. 2003. 144p. Tese (Doutorado em Fitopatologia) - Universidade Federal de Lavras, Lavras, 2003.

TANAKA, M.A.S.; CORREIA, M.V. Efeito do tratamento de feijão de diferentes qualidades sanitárias com fungicidas e antibióticos sobre a emergência e "stand". Fitopatologia Brasileira, v.7, p.339-347, 1982.

TORRES, S.B.; BRINGEL, J.M.M. Avaliação da qualidade sanitária e fisiológica de sementes de feijão macassar. Caatinga, Mossoró, v. 18, n. 2, p. 88-92, 2005. 
VECHIATO, M.H.; LASCA, C.C.; KOHARA, E.Y.; CHIBA, S. Efeito do tratamento de sementes de feijão (Phaseolus vulgaris) com fungicidas no controle e Macrophomina phaseolina e na emergência de plântulas. Arquivos do Instituto Biologico, v.67, n.1. s/p. 2000. http:// www.biologico.sp.gov.br/uploads/docs/arq/V67_1/feijao. htm. (acessado em 22 de abril de 2019).
VIANA, D.I.F. Incidência de colletotrichum lindemuthianum em sementes de feijão comum do grupo carioca (phaseolus vulgaris) procedentes de agricultores da região de BambuíMG. 2016. 30 f. TCC (Graduação) - Curso de Agronomia, Ciências Agrárias, Instituto Federal de Educação Ciencia e Tecnologia - Campus Bambuí, Bambuí-mg, 2016.

Recebido para publicação em 30/04/2019 e aprovado em 27/08/2019. 